\title{
Synthetic isoflavones and doping: A novel class of aromatase inhibitors?
}

\author{
Michele lannone $^{1,2} \mid$ Francesco Botrè ${ }^{1,3}$ (D) | Nicoletta Cardillo ${ }^{1} \mid$ Xavier de la Torre $^{1}$ (D)
}

${ }^{1}$ Laboratorio Antidoping, Federazione Medico Sportiva Italiana, Rome, Italy

${ }^{2}$ Dipartimento di Chimica e Tecnologia del Farmaco, "Sapienza" Università di Roma, Rome, Italy

${ }^{3}$ Dipartimento di Medicina Sperimentale, "Sapienza" Università di Roma, Rome, Italy

\section{Correspondence}

Francesco Botrè, Laboratorio Antidoping, Federazione Medico Sportiva Italiana, Largo Giulio Onesti, 1, 00197 Rome, RM, Italy. Email: francesco.botre@uniroma1.it

\begin{abstract}
Anectodical information suggests that flavonoids may be widely used among athletes for their multiple biochemical and pharmacological effects. We have evaluated in vitro the effects of two synthetic isoflavones, methoxyisoflavone and ipriflavone, on the catalytic activity of human aromatase (CYP19), the enzyme catalyzing the conversion of androgens (ie, testosterone or androstenedione) to estrogens (ie, estradiol and estrone). The potential inhibitory effect was evaluated by measuring the rate of aromatization of testosterone, monitored by gas chromatography-mass spectrometry (GC-MS), both in the presence and in the absence of methoxyisoflavone or ipriflavone, comparing their effects with those of synthetic aromatase inhibitors (formestane, anastrozole, and aminoglutethimide) presently included in the list of prohibited substances and methods, and of natural flavonoids (chrysin, quercetin, and daidzein), that are known inhibitors of CYP19. The preliminary results of our in vitro study show that methoxyisoflavone and ipriflavone act as competitive inhibitors of aromatase, the degree of inhibition measured in vitro being of the same order of magnitude of that of the aromatase inhibitors commonly used in anti-estrogenic therapies. Our preliminary in vitro results indicate that, in principle, a sufficiently large intake of isoflavones could alter the kinetics of the dynamic equilibria between androgens and estrogens, suggesting their monitoring in doping control routine analysis.
\end{abstract}

\section{KEYWORDS}

doping, synthetic flavonoids, ipriflavone, methoxyisoflavone, aromatase

\section{1 | INTRODUCTION}

Flavonoids are a broad class of low molecular weight compounds widely found in plants and fruit. They occur in common human diet and have been used as ingredients of drugs or food supplements. ${ }^{1,2}$ From a chemical point of view, flavonoids are characterized by a basic chemical structure consisting of two benzyl rings ( $A$ and $B$ ) joined by a three-carbon bridge which may or may not closed in a pyran ring (Figure 1A). According to the position of $B$ ring and to the level of unsaturation and oxidation of $C$ ring, flavonoids can be divided in different groups, including but not limited to flavones, isoflavones, flavonols, anthocyanins, and catechins.
Flavonoids have been used as anti-oxidants, anti-estrogenic agents, and androgen promoters. They have been shown to be endowed with many structure-dependent activities, leading to cytostatic, apoptotic, anti-inflammatory, anti-angiogenic, and hepatoprotective effects, ${ }^{3,4}$ and attracting attention also as possible chemoprotective or chemotherapeutic agents. ${ }^{5}$ In addition, several flavonoids are modulator of expressions and activity of specific cythocrome P450 genes and/or proteins. ${ }^{6}$ Nevertheless, due to their low concentration in food and to their non-optimal oral bioavailability, the actual effects of dietary flavonoids are moderately low. ${ }^{7}$ Among them, isoflavones, often classified as "phytoestrogens" due to their weak estrogenic activity, may be of interest in sports doping for their 


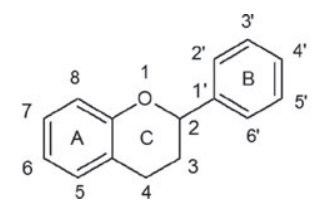

(A)

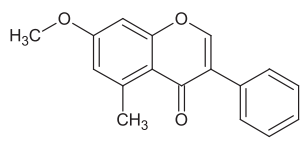

(C)

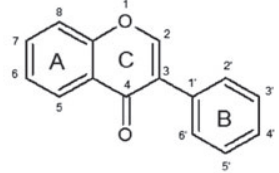

(B)

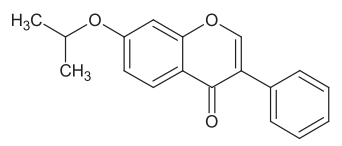

(D)
FIGURE 1 General structure of A, flavonoids and B, isoflavones and of $\mathrm{C}$, methoxyisoflvone and $\mathrm{D}$, ipriflavone

estrogenic and/or antioxidant properties. ${ }^{8,9}$ The isoflavones structure differs from the isomeric flavones only for the position of phenyl $B$ ring (Figure 1B). The consumption of food containing a large amount of flavonoids seems to be adjuvant for the course of cardiovascular diseases, cholesterolemia, premenstrual syndrome, menopause, and osteoporosis. ${ }^{10,11}$ For their medical and therapeutic interest, the most studied natural isoflavones are daidzein, genistein, and glycitein. ${ }^{12,13}$

Based on the biopharmacological properties of their natural analogs, synthetic isoflavones have been designed, synthesized, and studied for their biological effects. Among them, special attention has been focused on methoxyisoflavone (5-methyl-7-methoxy-isoflavone) (Figure 1C) and ipriflavone (7-isopropoxy-isoflavone) (Figure 1D). ${ }^{8}$

In the 1970s, animal studies showed the anabolic properties of methoxyisoflavone in terms of increased protein synthesis and decreased cortisol blood level. ${ }^{14}$ Human studies did not show significant modification of some key parameters usually considered in the assessment of anabolic properties (among them, body weight, body mass index, blood cortisol level, and isokinetic peak force) and for this reason the anabolic and ergogenic properties of methoxyisoflavone have not been further explored. ${ }^{15,16}$ Furthermore, focus on methoxyisoflavone in forensic toxicological analysis has been limited to the fact that its metabolites can cross-react with the antibodies used for the screening of synthetic cannabinoids, causing falsepositive results in urinary immunoassay. ${ }^{17}$

The use of ipriflavone is indicated in the treatment of osteoporosis in postmenopausal women ${ }^{18}$ due to its normalizing effects on calcitonin levels. Ipriflavone and its most abundant metabolite, 7-hydroxy-isoflavone, can also inhibit CYP1A2 and CYP2C9, leading to an increase in plasma levels of some drugs, including theophylline and tolbutamide. ${ }^{19}$

As for their effects on the estrogen metabolism and receptors, isoflavones are part of a group of substances of plant origin called "phytoestrogens" or "weak estrogens," due to the modulatory effects that exert al level of estrogen receptors, pregnane $X$ receptors, and constitutive androstane receptors. ${ }^{20-22}$ Although with an affinity approximately 5000 times lower than that of the estrogens, ${ }^{23}$ isoflavones can act as partial agonists or antagonists of the estrogen receptors, most probably through the inhibition of aromatase (CYP19), ${ }^{24-26}$ that is the enzyme that catalyzes the conversion of androstenedione and testosterone to estrone and estradiol respectively. ${ }^{27}$ The estrogenic/antiestrogenic activity of isoflavones may also be due to an alteration of biosynthesis and subsequent secretion of luteinizing hormone ( $\mathrm{LH})$, that acts stimulating the production of testosterone in male testicles, and that it is therefore included in the Prohibited List of the World Anti-Doping Agency (WADA), in section S2 (Peptide hormones, growth factors, related substances and mimetics), ${ }^{28}$ while isoflavones are non-prohibited substances.

The goal of the present work is to evaluate the effects of the two main synthetic isoflavones, methoxyisoflavone and ipriflavone, on the catalytic activity of the enzyme human aromatase (CYP19) by in vitro inhibition kinetics experiments monitored by gas chromatographymass spectrometry (GC-MS), comparing the entity of the effects with those produced by known inhibitors of aromatase, namely (a) natural flavonoids (chrysin, quercetin and daidzein), ${ }^{29-31}$ and (b) synthetic aromatase inhibitors already considered in the WADA Prohibited List (formestane, anastrozole, and aminoglutethimide, included in section S4 of Hormones and metabolic modulators).

\section{2 | EXPERIMENTAL}

\section{1 | Chemicals and reagents}

Testosterone, estradiol, formestane, aminoglutethimide, daidzein and quercetin were from Sigma-Aldrich (Milan, Italy); testosterone- $d_{3}$ (used as internal standard) was from the National Measurement Institute (NMI, Pymble, Australia); anastrozole was from TRC Canada (Toronto, Canada); chrysin was from Honeywell Fluka (Rodano, Italy); methoxyisoflavone and ipriflavone were supplied by LGC Standards (Sesto San Giovanni, Italy). The derivatizing agent was a mixture of $\mathrm{N}$-methyl- $\mathrm{N}$-trimethylsyliltrifluoroacetamide (MSTFA) / mercaptoethanol/ammonium iodide $\left(\mathrm{NH}_{4} \mathrm{l}\right)(1000: 6: 4 \mathrm{v} / \mathrm{v} / \mathrm{w})$ stored in screw-cap vials at $4^{\circ} \mathrm{C}$ for a maximum of two weeks. MSTFA was supplied by Chemische Fabrik Karl Bucher $\mathrm{GmbH}$ (Waldstetten, Germany); $\mathrm{NH}_{4} \mathrm{l}$ and mercaptoethanol were from Sigma-Aldrich (Milan, Italy). Solvents (tert-butylmethyl ether, ethyl acetate and methanol) and reagents (sodium phosphate and sodium hydrogen phosphate) were of analytical or high-performance liquid chromatography (HPLC) grade and provided by Sigma-Aldrich (Milan, Italy). Water was obtained from a MilliQ water purification system (Millipore S.p.A., Milan, Italy). The reagents (sodium phosphate buffer and the NADPH regenerating system consisting of magnesium chloride hexahydrate, NADP ${ }^{+}$, glucose-6-phosphate and glucose-6-phosphate dehydrogenase) for the in vitro study were purchased from GenTest (Tewksbury, MA, USA). Human aromatase (CYP19 + P450 reductase) was from Discovery Labware Inc (Woburn, MA, USA).

\section{2 | In vitro protocol}

Working solutions of testosterone $(0.1,0.2,0.5,1,5,10,20 \mu \mathrm{M})$ were prepared from a $50 \mu \mathrm{M}$ stock solution in methanol. Working solutions of inhibitors, prohibited drugs, and natural flavonoids, were prepared at different concentration, according to their $I C_{25}, I C_{50}$, and $I C_{75}$ (formestane, anastrozole, and aminoglutethimide 0.4, 0.8, $1.2 \mu \mathrm{M}$; daidzein 1, 5, $10 \mu \mathrm{M}$; chrysin 0.35, 0.7, $1 \mu \mathrm{M}$; quercetin 25, 50, 
$100 \mu \mathrm{M})$, in methanol. ${ }^{29-31}$ Stock solution of methoxyisoflavone and ipriflavone $(5,10,50 \mu \mathrm{M})$ were prepared in methanol. The incubation mixture, in a final volume of $150 \mu \mathrm{L}$, contained $0.1 \mathrm{M}$ sodium phosphate buffer, testosterone at final concentration of 1, 5, 10, 20, $50 \mu \mathrm{M}$, an NADPH regenerating system consisting of $3.3 \mathrm{mM}$ magnesium chloride, $1.3 \mathrm{mM} \mathrm{NADP}+, 3.3 \mathrm{mM}$ glucose 6-phosphate and $0.4 \mathrm{U} / \mathrm{mL}$ glucose-6-phosphate dehydrogenase. After mixture prewarming at $37^{\circ} \mathrm{C}$ for 5 minutes, the reaction, either in the absence or in the presence of different concentrations of the inhibitor, was started by adding $1 \mu \mathrm{M}$ of human aromatase. The samples were then incubated at $37^{\circ} \mathrm{C}$ up to 1440 minutes. One sample (negative control) containing all reaction components, but without the enzymatic protein, was also processed to monitor the potential non-enzymatic reactions possibly taking place during the incubation period. The overall reaction was terminated by the addition of $150 \mu \mathrm{L}$ of ice-cold acetonitrile. The reaction mixtures were then centrifuged (12 $000 \mathrm{rpm}$ for 7 minutes) before the sample purification. All incubations were performed in triplicate.

\section{3 | Sample preparation}

The supernatant of the samples obtained by the in vitro experiments were, after centrifugation, brought to dryness. $1 \mathrm{~mL}$ of phosphate buffer $0.8 \mathrm{M}\left(\mathrm{pH} \mathrm{7.4)}\right.$ and $100 \mu \mathrm{L}$ of the internal standard (testosterone- $d_{3}$ $0.5 \mu \mathrm{M}$ ) were added; the liquid/liquid extraction was carried out with $5 \mathrm{~mL}$ of tert-buthylmethyl ether for 5 minutes on a mechanical shaker. After centrifugation the organic layer was transferred to a $10 \mathrm{~mL}$ tube and evaporated to dryness. The residue was reconstituted in $50 \mu \mathrm{L}$ of the derivatizing mixture and the sample was maintained at $75^{\circ} \mathrm{C}$ for 30 minutes. Then a $1 \mu \mathrm{L}$ aliquot was injected into the GC-MS system.

\section{4 | Instrumental analysis}

Instrumental analysis was performed on an Agilent 6890/5973A gas chromatography-mass spectrometry (GC-MS) system (Agilent Technologies, Milan, Italy), in electron ionization (70 eV) mode, using an HP-1 fused silica capillary column (cross-linked methyl silicone, length $17 \mathrm{~m}$, i.d. $0.20 \mathrm{~mm}$, film thickness $0.11 \mu \mathrm{m}$; Agilent Technologies, Milan, Italy). The GC condition were as follows: the carrier gas helium at a flow rate of $1 \mathrm{~mL} / \mathrm{min}$; split ratio of 1/10; temperature program, $180^{\circ} \mathrm{C}$ (4.5-minute hold), $3^{\circ} \mathrm{C} / \mathrm{min}$ to $230^{\circ} \mathrm{C}, 20^{\circ} \mathrm{C} / \mathrm{min}$ to $290^{\circ} \mathrm{C}$ and $30^{\circ} \mathrm{C} / \mathrm{min}$ to $320^{\circ} \mathrm{C}$; the transfer line and injection temperature operated at $280^{\circ} \mathrm{C}$. The acquisition was performed in selected ion monitoring (SIM) mode. Identification was based on the specific retention time and on the characteristic diagnostic ions listed in Table 1. Quantitative determination of the concentration of testosterone and

TABLE 1 Retention time and characteristic ions for testosterone (T), estradiol $\left(E_{2}\right)$ and testosterone- $d_{3}\left(T-d_{3}\right)$

\begin{tabular}{llll} 
& $\begin{array}{l}\text { Retention } \\
\text { Time }(\mathrm{min})\end{array}$ & $\begin{array}{l}\text { Diagnostic } \\
\text { lon }(\mathrm{m} / \mathrm{z}) \mathbf{1}\end{array}$ & $\begin{array}{l}\text { Diagnostic } \\
\text { Ion }(\mathrm{m} / \mathrm{z}) \mathbf{2}\end{array}$ \\
\hline Testosterone $(\mathrm{T})$ & 14.11 & 432 & 417 \\
\hline Estradiol $\left(\mathrm{E}_{2}\right)$ & 13.93 & 416 & 285 \\
$\begin{array}{c}\text { Testosterone- } d_{3} \\
\left(\mathrm{~T}-d_{3}\right)\end{array}$ & 14.08 & 435 & 420 \\
\hline
\end{tabular}

(A)

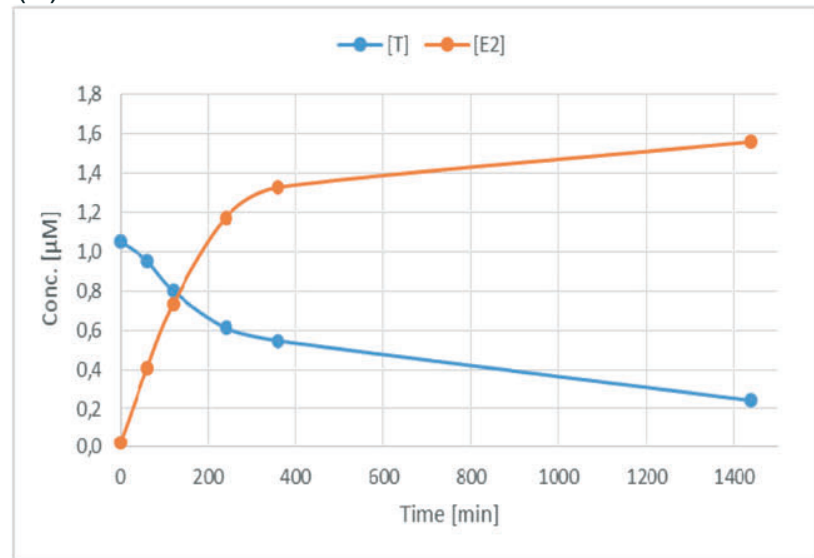

(B)

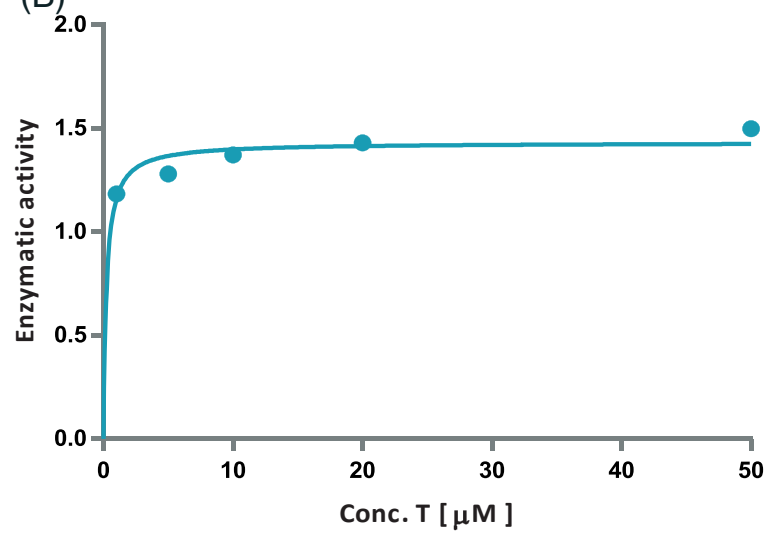

(C)

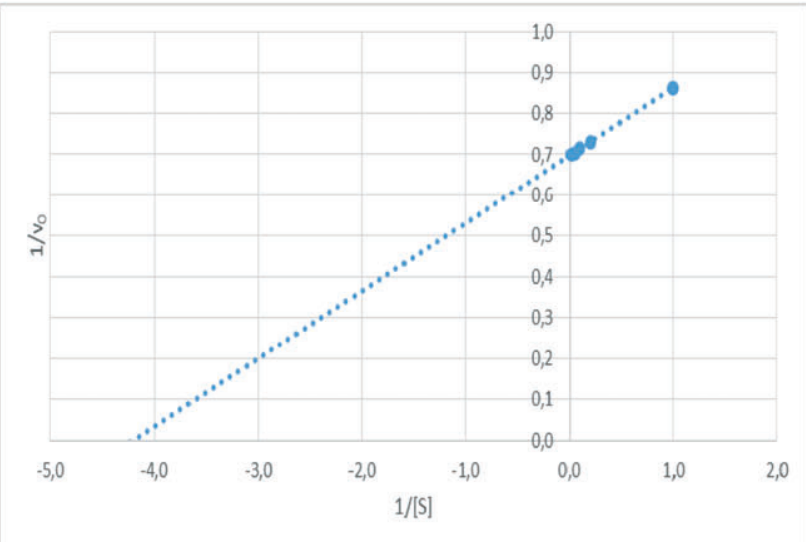

FIGURE 2 A, concentration of substrates vs time plot of the biotransformation of testosterone (T) in estradiol (E2); B,C, Michaelis-Menten and Lineweaver-Burk plot of the biotransformation of testosterone (T) in estradiol (E2) [Colour figure can be viewed at wileyonlinelibrary.com]

estradiol after enzymatic reaction was based on the peak area ratio of the analyte to the internal standard (testosterone- $d_{3}$ ).

\section{5 | Data analysis}

For peak integration and analyte quantification, a proprietary software of the GC-MS system was used. Peak integration was always doublechecked manually.

Michaelis-Menten's kinetic constant $\left(\mathrm{K}_{\mathrm{m}}\right)$ and the maximum velocity of reaction $\left(V_{\text {max }}\right)$ of the biotransformation of testosterone in estradiol were evaluated by nonlinear regression analysis carried 
out using GraphPad Prism version 7.0 (GraphPad Software Inc., San Diego, CA, USA). The inhibition constant's value $\left(K_{i}\right)$ of the biotransformation of testosterone to estradiol in the presence of different concentration of methoxyisoflavone and ipriflavone $(5,10$, $50 \mu \mathrm{M})$ was evaluated through graphical analysis of Lineweaver-Burk plot and by fitting data into competitive, uncompetitive, non-competitive and mixed inhibition models by nonlinear regression analysis carried out using GraphPad Prism version 7.0.

(A)

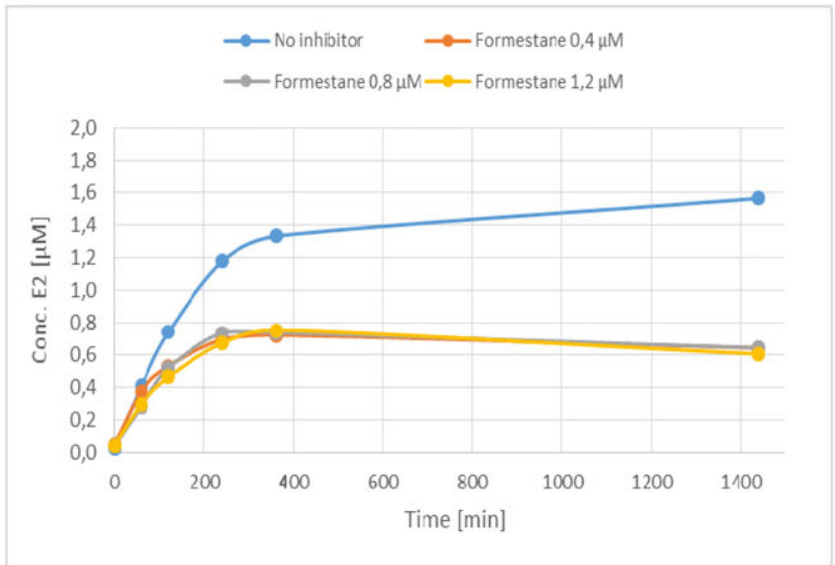

(B)

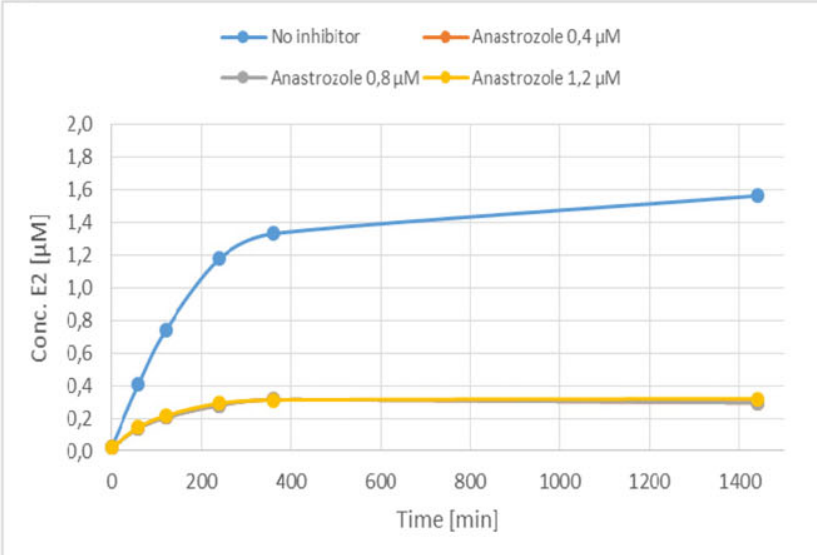

(C)

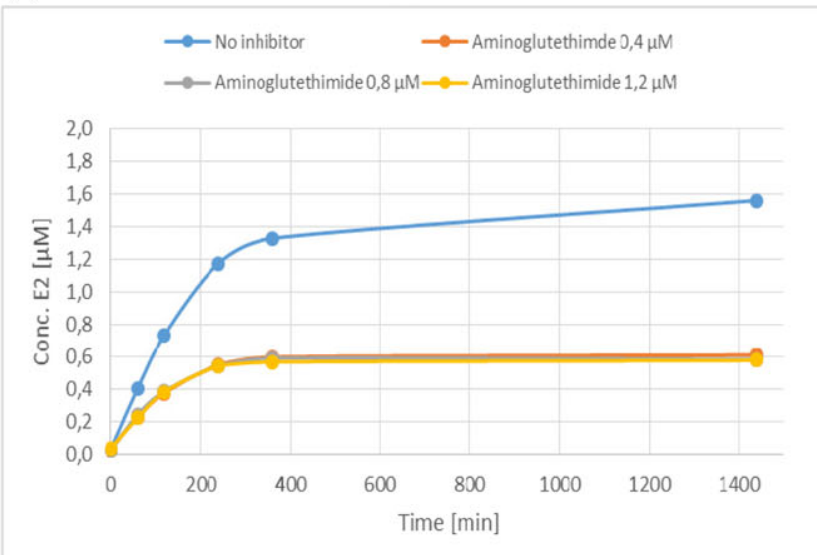

FIGURE 3 Concentration of substrate (E2) vs time plot of the biotransformation of testosterone in estradiol without and the in the presence of $\mathrm{A}$, formestane, $\mathrm{B}$, anastrozole, and $\mathrm{C}$, aminoglutethimide in three different concentrations $(\mu \mathrm{M})$ [Colour figure can be viewed at wileyonlinelibrary.com]

\section{3 | RESULTS AND DISCUSSION}

\section{1 | In vitro biotransformation of testosterone to estradiol in the presence of CYP19}

To preliminarily verify the reliability of the data obtained in our in vitro metabolism studies, the biotransformation of testosterone to estradiol was preliminarily followed in the absence of inhibitors. As expected, a

(A)

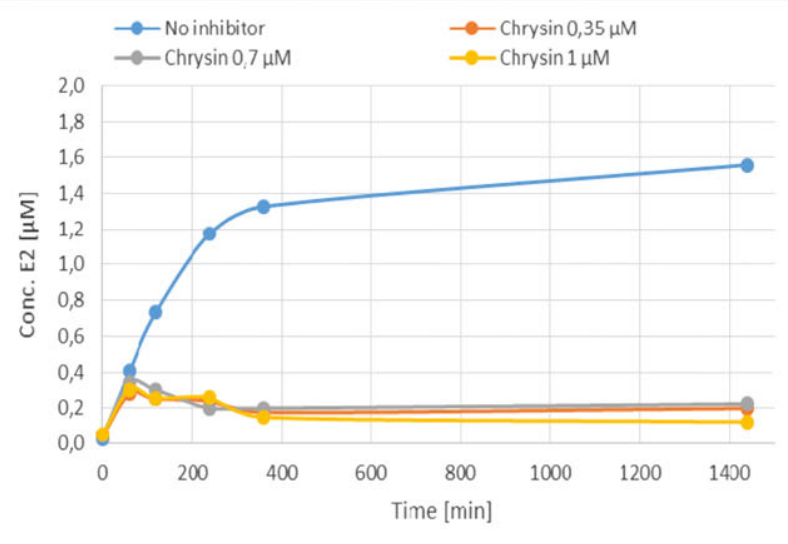

(B)

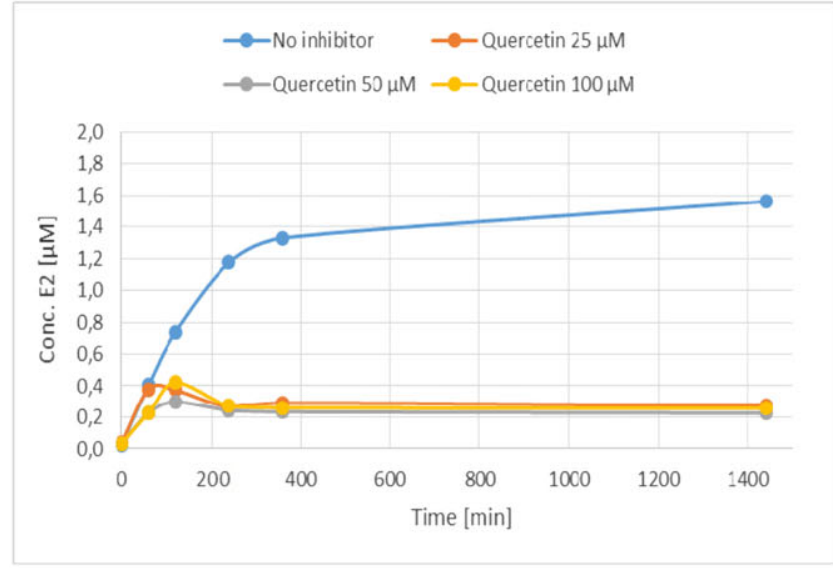

(C)

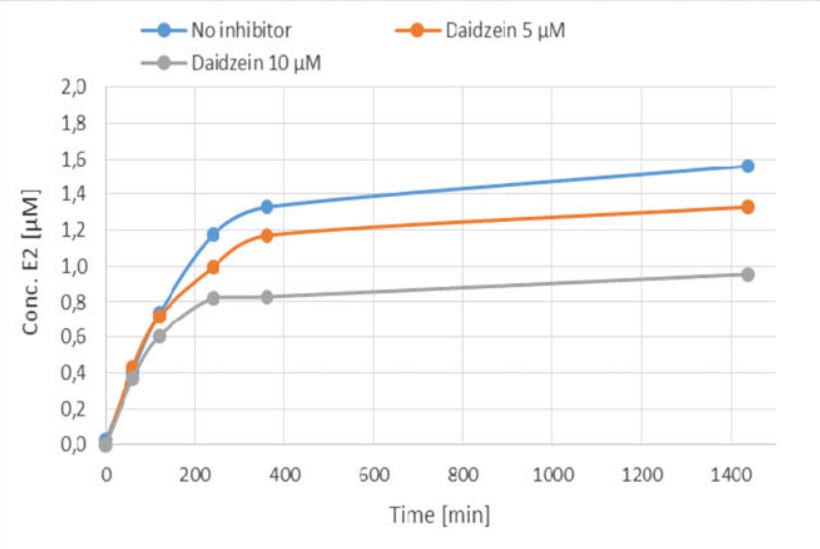

FIGURE 4 Concentration of substrate (E2) vs time plot of the biotransformation of testosterone in estradiol without and in presence of $A$, chrysin , B, quercetin, and C, daidzein in two (daidzein) and three different concentrations $(\mu \mathrm{M})$ [Colour figure can be viewed at wileyonlinelibrary.com] 
decrease in testosterone concentration and a parallel increase of estradiol concentration were observed. To calculate the kinetic parameters of the in vitro biotransformation of testosterone to estradiol the substrate was incubated, at different concentration $(1,5,10,20,50 \mu \mathrm{M})$, for 1440 minutes. Michelis-Menten plot, Lineweaver-Burk plot, $\mathrm{K}_{\mathrm{m}}(1.43 \mu \mathrm{M})$ and $\mathrm{V}_{\max }\left(0.24 \mathrm{mM} \mathrm{s}^{-1}\right)$ were
(A)
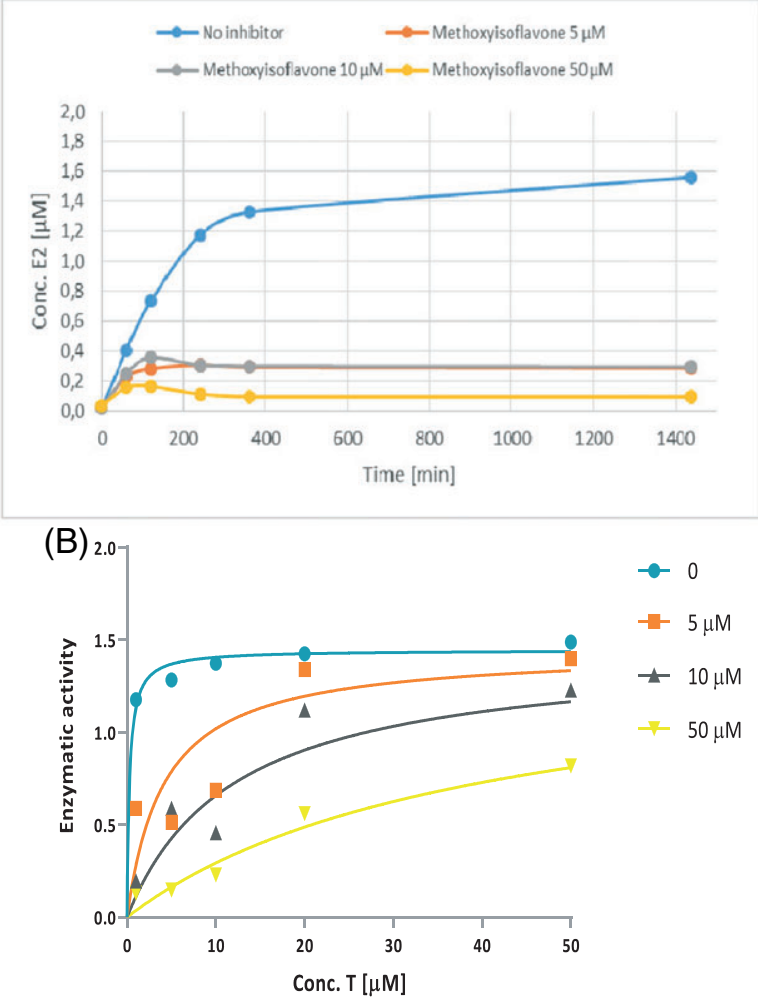

(C)

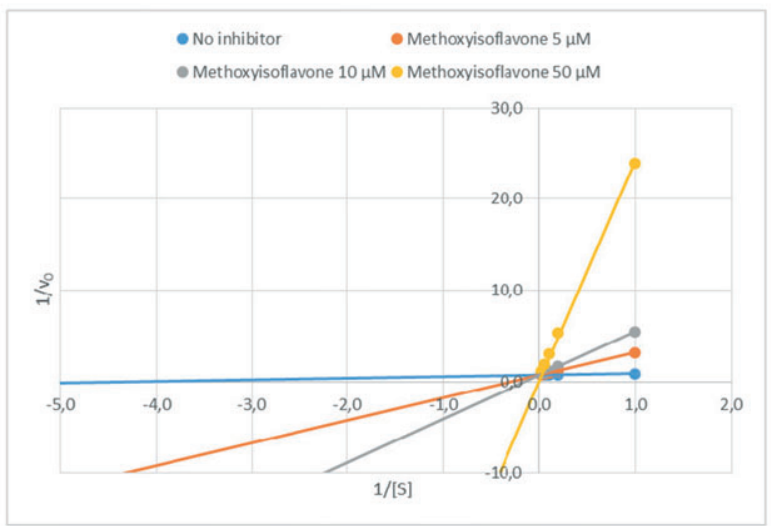

(D)

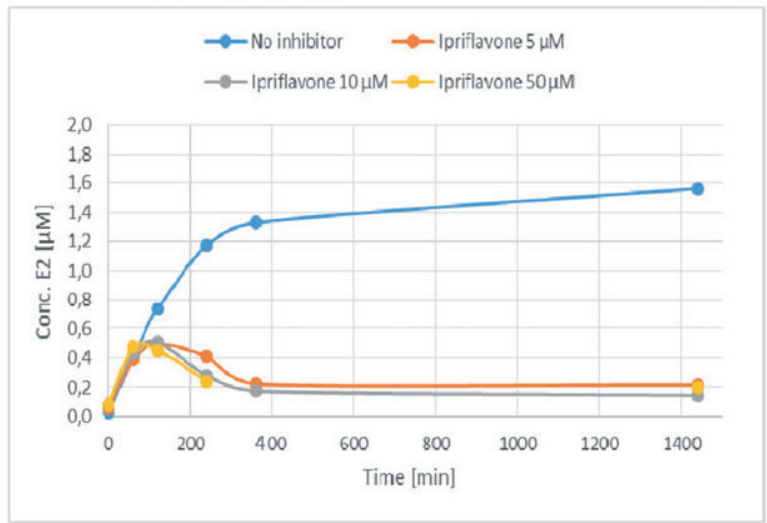

(E)

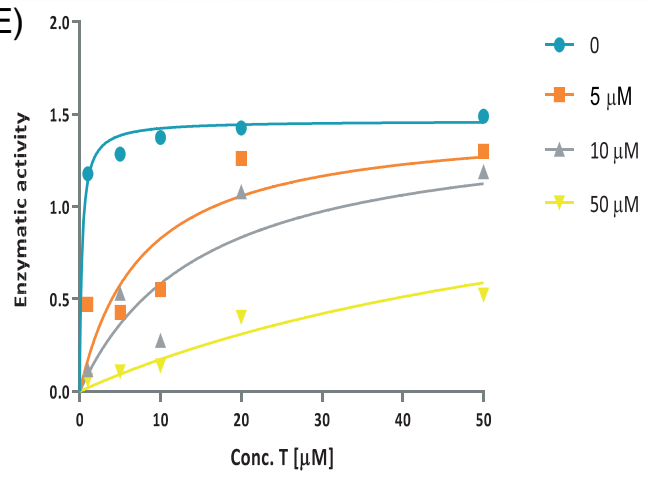

$(\mathrm{F})$

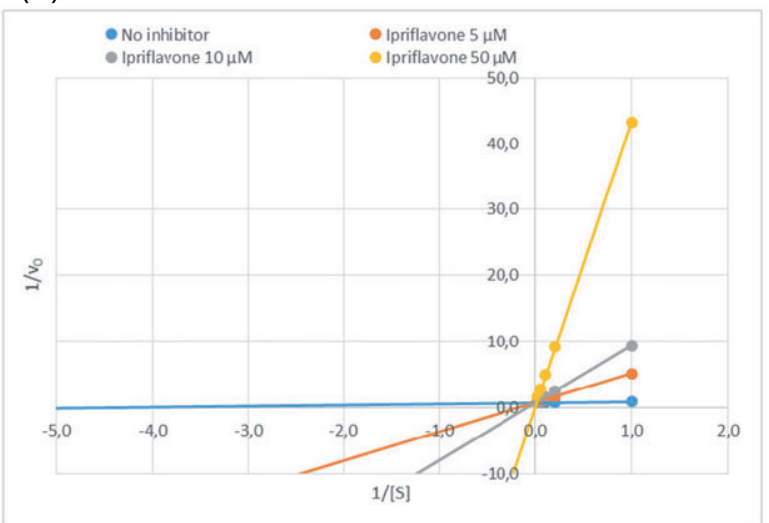

FIGURE 5 Concentration of substrate (E2) vs time plot of the biotransformation of testosterone in estradiol without and in presence of A, methoxyisoflavone and $\mathrm{D}$, ipriflavone in three different concentrations $(\mu \mathrm{M})$; Michaelis-Menten plot and Lineweaver plot of the biotransformation of testosterone in estradiol in presence, respectively, of three different concentration ( $\mu \mathrm{M})$ of $\mathrm{B}, \mathrm{C}$, methoxyisoflavone and $\mathrm{E}$, F, ipriflavone [Colour figure can be viewed at wileyonlinelibrary.com]

TABLE 2 Inhibition kinetic constant $\left(\mathrm{K}_{\mathrm{i}}\right)$ and type of inhibition for all compounds studied

\begin{tabular}{|c|c|c|c|}
\hline & & $\mathrm{K}_{\mathrm{i}}(\mu \mathrm{M})$ & Inhibition Type \\
\hline Aromatase inhibitor drugs & $\begin{array}{l}\text { Formestane } \\
\text { Anastrozole } \\
\text { Aminoglutethimide }\end{array}$ & $0.20<\mathrm{K}_{\mathrm{i}}<0.65^{29-31}$ & $\begin{array}{l}\text { Competitive suicide } \\
\text { Competitive reversible } \\
\text { Competitive reversible }\end{array}$ \\
\hline Natural flavonoids & $\begin{array}{l}\text { Chrysin } \\
\text { Quercetin } \\
\text { Daidzein }\end{array}$ & $2.20<\mathrm{K}_{\mathrm{i}}<2.80^{29-31}$ & $\begin{array}{l}\text { Competitive } \\
\text { Competitive } \\
\text { Competitive }\end{array}$ \\
\hline Synthetic isoflavones & $\begin{array}{l}\text { Methoxyisoflavone } \\
\text { Ipriflavone }\end{array}$ & $\begin{array}{l}0.36 \\
0.19\end{array}$ & $\begin{array}{l}\text { Competitive } \\
\text { Competitive }\end{array}$ \\
\hline
\end{tabular}


obtained by non-linear regression analysis. The low value of $K_{m}$ is related to the remarkable affinity of testosterone with human aromatase, in our in vitro model (Figure 2A-C).

\subsection{In vitro inhibition of CYPY9 by formestane, anastrozole, and aminoglutethimide}

Successively, to validate our in vitro model systems also for the study of CYP19 inhibition, we evaluated the effects of the synthetic aromatase inhibitors formestane, anastrozole, and aminoglutethimide, on the in vitro biotransformation of testosterone to estradiol. More specifically, formestane is a steroidal, competitive, and irreversible inhibitor of human aromatase, while anastrozole and aminoglutethimide are non-steroidal, competitive and reversible inhibitors. ${ }^{32}$ These drugs are clinically used to treat postmenopausal breast cancer and other estrogen-dependent disease. After the incubation of different concentrations $(0.4,0.8$, and $1.2 \mu \mathrm{M})$ of each drugs with $1 \mu \mathrm{M}$ of substrate (testosterone), a pronounced reduction of estradiol concentration was observed, this effect being independent of the concentration of banned drug. These results confirmed that formestane, anastrozole, and aminoglutethimide resulted as competitive inhibitors of CYP19 also in our in vitro model system (Figure $3 \mathrm{~A}-\mathrm{C}$ ).

\section{3 | In vitro inhibition of CYPY9 by chrysin, quercetin and daidzein}

Furthermore, the same in vitro assays were also performed in the presence of chrysin, quercetin, and daidzein. Chrysin and quercetin are natural flavones while daidzein is a natural isoflavone. Despite their in vitro inhibition effects on the catalytic activity of aromatase is well-documented, ${ }^{29-31}$ these substances are not banned or subject to monitoring by WADA. After incubation at different concentrations, in the previously described experimental conditions, the inhibitory effect was assessed to be concentration-independent for chrysin and quercetin, and concentration-dependent for daidzein. (Figure 4A-C).

\subsection{In vitro inhibition of CYPY9 by ipriflavone and methoxyisoflavone}

Having therefore preliminarily verified the reliability of the results obtained in our in vitro model system, we proceeded with the assessment, in the same experimental conditions, of the potential effects of ipriflavone and methoxyisoflavone on the catalytic activity of aromatase. The in vitro biotransformation of testosterone to estradiol catalyzed by CYP19 was studied in the presence of different concentrations of either one of the two synthetic isoflavones (methoxyisoflavone and ipriflavone) specifically considered in this study. After the incubation at different concentrations $(5,10$, $50 \mu \mathrm{M}$ ), a decrease of the rate of formation of estradiol was recorded, this effect being concentration-dependent for methoxyisoflavone and concentration-independent for ipriflavone. To evaluate the kinetic parameters of the in vitro biotransformation of testosterone in estradiol, the substrate (testosterone) was incubated, at different concentrations $(1,5,10,20,50 \mu \mathrm{M})$, for 1440 minutes with different concentrations of methoxyisoflavone or ipriflavone at 5, 10, and
$50 \mu \mathrm{M}$. The results obtained after a non-linear regression analysis show that $K_{i}$ value for methoxyisoflavone is $0.36 \mu \mathrm{M}$ and for ipriflavone is $0.19 \mu \mathrm{M}$. Michaelis-Menten plot and Lineweaver-Burk plot show that methoxyisoflavone and ipriflavone inhibit in a competitive manner human aromatase (Figure 5A-F).

The $K_{i}$ values obtained for synthetic isoflavones are of the same order of magnitude of those of banned drugs, and significantly smaller than those of natural flavones considered in the study (Table 2).

\section{5 | Conclusions}

The results obtained in our in vitro model system show that, in the range of concentrations here considered, methoxyisoflavone, and ipriflavone have a potential for aromatase inhibition similar to that of formestane, anastrozole, and aminoglutethimide, that are drugs used in anticancer therapy and banned by the WADA for their effects on steroidogenesis. Clearly, the results here presented are not sufficient to express a final opinion on the opportunity of including synthetic isoflavones on WADA's Prohibited List, since the actual magnitude of their in vivo effects would certainly be modulated by their pharmacokinetic properties, and especially by their low bioavailability. ${ }^{33}$ Nonetheless, we believe their monitoring could still be useful in doping control analysis, also considering the high dosages recommended for synthetic isoflavones in dietary supplements. For indeed, regardless the in vivo pharmacokinetic effects, the intake of synthetic isoflavones, especially in association with prohibited androgens, their precursors and/or metabolites, could alter the kinetics of the dynamic equilibria between androgens and estrogens, also potentially affecting some parameters of the steroidal module of the athlete biological passport (ABP).

\section{ORCID}

Francesco Botrè (D) http://orcid.org/0000-0001-5296-8126

Xavier de la Torre (D) http://orcid.org/0000-0001-8037-6750

\section{REFERENCES}

1. Beecher GR. Overview of dietary flavonoids: nomenclature, occurrence and intake. J Nutr. 2003;133(10):3248S-3254S.

2. Chun OK, Chung SJ, Song WO. Estimated dietary flavonoid intake and major food sources of US adults. J Nutr2007. 2007;137(5):1244-1252.

3. Middleton E, Kandaswami C, Theoharides T. The effects of plant flavonoids on mammalian cells: implications for inflammation, heart disease, and cancer. Pharmacol Rev. 2000;52(4):673-751.

4. Arkhipov V, Smlrllov M, Khilya V. Chemistry of modified flavonoids. Chem Heterocycl Compd. 1997;33(5):515-519.

5. Zand RSR, Jenkins DJ, Diamandis EP. Steroid hormone activity of flavonoids and related compounds. Breast Cancer Res Treat. 2000;62(1):35-49.

6. Kuiper GG, Lemmen JG, Carlsson BO, et al. Interaction of estrogenic chemicals and phytoestrogens with estrogen receptor $\beta$. Endocrinology. 1998;139(10):4252-4263.

7. Moon YJ, Wang X, Morris ME. Dietary flavonoids: effects on xenobiotic and carcinogen metabolism. Toxicol In Vitro. 2006;20(2):187-210.

8. Lecompte Y, Rosset M, Richeval C, Humbert L, Arpino P. UPLC-ESI-QTOF-MS ${ }^{E}$ identification of urinary metabolites of the emerging sport nutrition supplement methoxyisoflavone in human subjects. J Pharm Biomed Anal. 2014;96:127-134. 
9. Appolonova S, Baranov P, Rodchenkov G. Metabolism of non-steroidal phytoestrogens: ipriflavone and 5-methyl-7-hydroxy-isoflavone. In: Recent Advances in Doping Analysis (14) - Proceedings of the 24th Cologne Workshop, 4-9-June 2006, (Eds: W. Schänzer, H. Geyer, A. Gotzman, U. Mareck). Sportverlag Strauss, Köln, 2006, pp 91-100.

10. Peterson JJ, Dwyer JT, Jacques PF, McCullough ML. Associations between flavonoids and cardiovascular disease incidence or mortality in European and US populations. Nutr Rev. 2012;70(9):491-508.

11. Sarkar FH, Li Y. Soy isoflavones and cancer prevention. Cancer Invest. 2003;21(5):744-757.

12. Heinonen SM, Wähälä K, Adlercreutz $\mathrm{H}$. Metabolism of isoflavones in human subjects. Phytochem Rev. 2002;1(2):175-182.

13. Koh E, Mitchell AE. Characterization of urinary isoflavone metabolites excreted after the consumption of soy flour or soybean paste using LC-(ESI) MS/MS. J Food Biochem. 2011;35(5):1474-1485.

14. Kreider RB, Wilborn CD, Taylor L, et al. ISSN exercise \& sport nutrition review: research \& recommendations. J Int Soc Sports Nutr. 2010;7(1):7-50.

15. Incledon T, Van Gammeren D, Antonio J. The effects of 5-methyl-7methoxyisoflavone on body composition and performance in collegeaged men. Med Sci Sports Exerc. 2001;33(5):S338.

16. Wilborn CD, Taylor LW, Campbell BI, et al. Effects of methoxyisoflavone, ecdysterone, and sulfo-polysaccharide supplementation on training adaptations in resistance-trained males. J Int Soc Sports Nutr. 2006;3(2):19-27.

17. Lecompte $Y$, Perrin M, Daude B, Arpino P. Méthoxyisoflavone et dépistage du cannabis dans les urines: mise en évidence d'une réaction croisée peu connue. Ann Toxicol Anal. 2012;24(1):49-58.

18. Yamazaki I, Kinoshita M. Calcitonin secreting property of ipriflavone in the presence of estrogen. Life Sci 1986. 1986;38(17):1535-1541.

19. Monostory K, Vereczkey L, Lévai F, Szatmári I. Ipriflavone as an inhibitor of human cytochrome P450 enzymes. Br J Pharmacol. 1998;123(4):605-610.

20. Setchell KD, Cassidy A. Dietary isoflavones: biological effects and relevance to human health. J Nutr. 1999;129(3):758S-767S.

21. Cassetta A, Stojan J, Krastanova I, et al. Structural basis for inhibition of $17 \beta$-hydroxysteroid dehydrogenases by phytoestrogens: the case of fungal 17ß-HSDcl. J Steroid Biochem Mol Biol. 2017;171:80-93.
22. Kristan K, Krajnc K, Konc J, Gobec S, Stojan J, Rižner TL. Phytoestrogens as inhibitors of fungal $17 \beta$-hydroxysteroid dehydrogenase. Steroids. 2005;70(9):626-635.

23. Cos P, De Bruyne T, Apers S, Berghe DV, Pieters L, Vlietinck AJ. Phytoestrogens: recent developments. Planta Med. 2003;69(7): 589-599.

24. Pelissero C, Lenczowski MJP, Chinzi D, Davail-Cuisset B, Sumpter JP, Fostier A. Effects of flavonoids on aromatase activity, an in vitro study. J Steroid Biochem Mol Biol. 1996;57(3):215-223.

25. Ta N, Walle T. Aromatase inhibition by bioavailable methylated flavones. J Steroid Biochem Mol Biol. 2007;107(1):127-129.

26. Kao YC, Zhou C, Sherman M, Laughton CA, Chen S. Molecular basis of the inhibition of human aromatase (estrogen synthetase) by flavone and isoflavone phytoestrogens: a site-directed mutagenesis study. Environ Health Perspect. 1998;106(2):85-92.

27. Akhtar M, Calder MR, Corina DL, Wright JN. Mechanistic studies on C-19 demethylation in oestrogen biosynthesis. Biochem J. 1982;201(3):569-580.

28. WADA. International standard - the prohibited list 2017. https:// www.wada-ama.org/en/prohibited-list.

29. Hodek P, Trefil P, Stiborová M. Flavonoids-potent and versatile biologically active compounds interacting with cytochromes P450. Chem Biol Interact. 2002;139(1):1-21.

30. Stresser DM, Turner SD, McNamara J, et al. A high-throughput screen to identify inhibitors of aromatase (CYP19). Anal Biochem. 2000;284(2):427-430.

31. Kellis JT Jr, Vickery LE. Inhibition of human estrogens synthetase (aromatase) by flavones. Science. 1984;225(4666):1032-1035.

32. Mokbel K. The evolving role of aromatase inhibitors in breast cancer. Int J Clin Oncol. 2002;7(5):279-283.

33. Neal MD, Yanez JA. Flavonoids pharmacokinetics: methods of analysis, preclinical and clinical pharmacokinetics, safety and toxicology. 1st ed. New York: John Wiley \& Sons, Inc; 2013.

How to cite this article: lannone $M$, Botrè $F$, Cardillo $N$, de la Torre X. Synthetic isoflavones and doping: A novel class of aromatase inhibitors?. Drug Test Anal. 2019;11:208-214. https://doi.org/10.1002/dta.2482 